\title{
It Is High Time That We Define Axial Psoriatic Arthritis
}

Psoriatic arthritis (PsA), one of the spondyloarthritides (SpA), is an inflammatory musculoskeletal disease associated with psoriasis, classified according to the ClASsification for Psoriatic Arthritis (CASPAR) criteria ${ }^{1}$. PsA is a heterogeneous disease; manifestations vary within and between patients and commonly involve the skin, joints, and occasionally the eye and gastrointestinal $\operatorname{tract}^{2}$. With the aim to better study the most common manifestations of PsA, clinical trials and treatment recommendations have classified the cutaneous and musculoskeletal manifestations into domains ${ }^{3}$. These include skin, nails, peripheral arthritis, enthesitis, dactylitis, and axial arthritis ${ }^{3}$. Experts in PsA have largely reached consensus on the definition and tools for assessment of skin, nails, peripheral arthritis, enthesitis, and dactylitis. Recent clinical trials have provided evidence of varying efficacy of interventions for active disease in these domains ${ }^{4}$.

PsA patients with axial arthritis (axPsA) tend to have more severe disease ${ }^{5}$. Compared to those without axial disease, these patients have higher likelihood of moderate/ severe psoriasis, higher disease activity, and greater effect on quality of life and function ${ }^{5}$. Therefore, determining whether the axial domain is involved may have prognostic value. However, the axial arthritis domain is the least studied; the tools of assessment and treatment recommendations have been borrowed from axial SpA including ankylosing spondylitis (AS), with the presumption that axPsA is similar to AS/axial $\mathrm{SpA}^{6}$. This may not be true because there are significant differences between AS and axPsA ${ }^{7}$.

Smoking is an important environmental risk factor for the development of psoriasis, PsA, and AS and is associated with worse outcomes ${ }^{8,9,10,11,12}$. With the hypothesis that similar risk factors may operate in the development of AS and axPsA, Solmaz, et al have investigated the association between smoking and axPsA in a large prospective, multicenter PsA registry. In this issue of the Journal, they report that in this cohort of 1535 patients with PsA from Turkey, Canada, and Italy, at study entry current smoking was significantly associated with both axPsA and radiographic sacroiliitis ${ }^{13}$. The authors conclude that these observations are similar to those in AS and that smoking cessation may help prevent development of axPsA in patients with psoriasis.

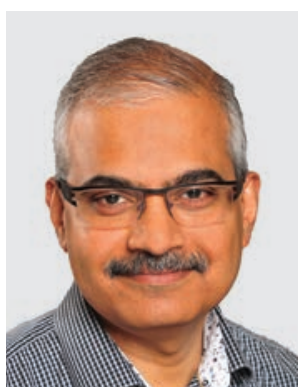

The authors must be congratulated on developing the PsA-International Database (PsArt-ID) registry that now spans 3 countries and has recruited $>1500$ patients with $\mathrm{PsA}^{14}$. Such large registries will allow collection of realworld data, provide real-world evidence, and complement similar studies done elsewhere. However, the study also illustrates some of the challenges in conducting such registry-based studies.

As discussed in the literature, there is no consensus on the definition of axPsA. Presence or absence of axial symptoms such as inflammatory back pain is a poor indicator of the likelihood of having axPsA ${ }^{15}$. Moreover, a quarter of patients with axPsA may have symptomatically silent axial disease $^{16}$. Experts believe that radiological evidence (by radiography or magnetic resonance imaging) of involvement of the sacroiliac joints or spine should be an important criterion for identifying axPsA. The major limitation of the study by Solmaz, et al is that axPsA was defined by "clinician's decision of axPsA" based primarily on the presence of inflammatory back pain and their "final judgement"; imaging was not mandated. Up to $70 \%$ of patients with axPsA were judged to have inflammatory back pain. The features used to define axPsA in the rest are unclear. Therefore, the risk of misclassification is high.

About $30 \%$ of the patients were reported to have axPsA according to the definition used. This estimate is similar to reports from cohorts where the definition is based on imaging ${ }^{17}$. However, patients with axPsA in the study by Solmaz, et al were similar to those without axPsA regarding activity in peripheral joints and entheses, HLA-B27 status, pain, fatigue, the Bath AS Disease Activity Index (a measure of axial disease activity in AS and axSpA), Disease Activity Index for Psoriatic Arthritis score, the proportion of patients satisfying criteria for minimal disease activity, and physical function as measured by the Health Assessment Questionnaire (HAQ) and Bath Ankylosing Spondylitis Functional Index ${ }^{13}$. Polyarthritis was more prevalent in non-axial PsA. This is not in line with previous reports that have indicated that PsA patients with axPsA have more severe disease compared to those without axPsA, and higher prevalence of HLA-B27 $7^{5,17}$. Thus, the effect of misclassification in this study is unclear.

See Smoking in axial PsA, page 1354

Personal non-commercial use only. The Journal of Rheumatology Copyright $(\subset) 2020$. All rights reserved. 
However, it is reassuring that in the small subset of patients for whom data for the presence of radiographic sacroiliitis are available, current smoking was strongly associated with radiographic sacroiliitis and these patients had a higher HAQ score.

The lack of a clear definition and possible misclassification of disease status may also influence the primary study conclusion that current smoking is associated with axPsA. No association was found with being an ex-smoker and with pack-years of smoking. Moreover, the cross-sectional nature of the study precludes inferences on causality.

Despite many caveats, the study indicates that current smoking is associated with the presence of axPsA. This is important because smoking as well as axPsA is associated with more severe disease. If smoking is causally related to severe disease including axPsA, smoking cessation will provide additional benefit in patients with psoriasis and PsA. However, such research is hampered by the lack of a proper definition of axPsA.

Thankfully, preparation for a large study to define axPsA under the auspices of Assessment of Spondyloarthritis international Society and Group for Research and Assessment of Psoriasis and Psoriatic Arthritis is under way. It is likely that the definition of axPsA will be heavily anchored on the presence of imaging abnormalities. Therefore, studies investigating risk factors or outcomes of axPsA would require axial imaging. This will significantly increase cost and add the additional complexity of reliably scoring the images. Nevertheless, longitudinal studies with inception cohorts of PsA/psoriasis patients with validated definitions and quality data collection and management, and adequate resources will likely provide answers to these important questions.

\author{
VINOD CHANDRAN®, DM, PhD, \\ Division of Rheumatology, \\ Associate Professor, \\ Department of Medicine, \\ Department of Laboratory Medicine and \\ Pathobiology, \\ Institute of Medical Science, \\ University of Toronto, \\ Affiliate Scientist, \\ Krembil Research Institute, \\ University Health Network, \\ Toronto, Ontario, \\ Adjunct Professor, \\ Memorial University, \\ St. John's, Newfoundland and Labrador, \\ Canada.
}

Address correspondence to V. Chandran, 1E-416, Toronto Western Hospital, 399 Bathurst St., Toronto, Ontario M5T2S8, Canada. E-mail: vinod.chandran@uhnresearch.ca.V.Chandran has received research grants from AbbVie and Celgene. His spouse is an employee of Eli Lilly.

\section{REFERENCES}

1. Taylor W, Gladman D, Helliwell P, Marchesoni A, Mease P, Mielants $\mathrm{H}$, et al. Classification criteria for psoriatic arthritis: development of new criteria from a large international study. Arthritis Rheum 2006;54:2665-73.
2. Ritchlin CT, Colbert RA, Gladman DD. Psoriatic arthritis. N Engl J Med 2017:376:957-70.

3. Coates LC, Kavanaugh A, Mease PJ, Soriano ER, Laura Acosta-Felquer M, Armstrong AW, et al. Group for Research and Assessment of Psoriasis and Psoriatic Arthritis 2015 Treatment Recommendations for Psoriatic Arthritis. Arthritis Rheumatol 2016;68:1060-71.

4. Mease PJ, Smolen JS, Behrens F, Nash P, Liu Leage S, Li L, et al. A head-to-head comparison of the efficacy and safety of ixekizumab and adalimumab in biological-naive patients with active psoriatic arthritis: 24-week results of a randomised, open-label, blinded-assessor trial. Ann Rheum Dis 2020;79:123-31.

5. Mease PJ, Palmer JB, Liu M, Kavanaugh A, Pandurengan R, Ritchlin CT, et al. Influence of axial involvement on clinical characteristics of psoriatic arthritis: analysis from the Corrona Psoriatic Arthritis/Spondyloarthritis registry. J Rheumatol 2018;45:1389-96.

6. Chandran V. Psoriatic spondylitis or ankylosing spondylitis with psoriasis: same or different? Curr Opin Rheumatol 2019;31:329-34.

7. Feld J, Chandran V, Haroon N, Inman R, Gladman D. Axial disease in psoriatic arthritis and ankylosing spondylitis: a critical comparison. Nat Rev Rheumatol 2018;14:363-71.

8. Lee EJ, Han KD, Han JH, Lee JH. Smoking and risk of psoriasis: a nationwide cohort study. J Am Acad Dermatol 2017;77:573-5.

9. Nguyen UDT, Zhang Y, Lu N, Louie-Gao Q, Niu J, Ogdie A, et al. Smoking paradox in the development of psoriatic arthritis among patients with psoriasis: a population-based study. Ann Rheum Dis 2018;77:119-23

10. Videm V, Cortes A, Thomas R, Brown MA. Current smoking is associated with incident ankylosing spondylitis -- the HUNT population-based Norwegian health study. J Rheumatol 2014;41:2041-8.

11. Shimabuco AY, Gonçalves CR, Moraes JCB, Waisberg MG, Ribeiro AC de M, Sampaio-Barros PD, et al. Factors associated with ASDAS remission in a long-term study of ankylosing spondylitis patients under tumor necrosis factor inhibitors. Adv Rheumatol 2018;58:40.

12. Tillett W, Jadon D, Shaddick G, Cavill C, Korendowych E, de Vries CS, et al. Smoking and delay to diagnosis are associated with poorer functional outcome in psoriatic arthritis. Ann Rheum Dis 2013;72:1358-61.

13. Solmaz D, Kalyoncu U, Tinazzi I, Bakirci S, Bayindir O, Dogru A, et al. Current smoking is increased in axial psoriatic arthritis and radiographic sacroiliitis. J Rheumatol 2020;47:1354-8.

14. Kalyoncu U, Bayindir Ö, Ferhat Öksüz M, Doğru A, Kimyon G, Tarhan EF, et al. The Psoriatic Arthritis Registry of Turkey: results of a multicentre registry on 1081 patients. Rheumatology 2017;56:279-86.

15. Yap KS, Ye JY, Li S, Gladman DD, Chandran V. Back pain in psoriatic arthritis: defining prevalence, characteristics and performance of inflammatory back pain criteria in psoriatic arthritis. Ann Rheum Dis 2018;77:1573-7.

16. Jadon DR, Sengupta R, Nightingale A, Lindsay M, Korendowych E, Robinson G, et al. Axial Disease in Psoriatic Arthritis study: defining the clinical and radiographic phenotype of psoriatic spondyloarthritis. Ann Rheum Dis 2017;76:701-7.

17. Chandran V, Tolusso DC, Cook RJ, Gladman DD. Risk factors for axial inflammatory arthritis in patients with psoriatic arthritis. J Rheumatol 2010;37:809-15.

J Rheumatol 2020;47:1301-2; doi:10.3899/jrheum.200103

Personal non-commercial use only. The Journal of Rheumatology Copyright @ 2020 . All rights reserved. 